\title{
Molecular and Pathogenic Diversity of the Causal Agents of Onion Leaf Twister Disease in Batticaloa District of Sri Lanka
}

\author{
Vengadaramana A. ${ }^{1,2, *}$, D. M. De Costa ${ }^{3}$ \\ ${ }^{1}$ Postgraduate Institute of Agriculture, University of Peradeniya, Sri Lanka \\ ${ }^{2}$ Department of Botany, Faculty of Science, University of Jaffna, Sri Lanka \\ ${ }^{3}$ Department of Agricultural Biology, Faculty of Agriculture, University of Peradeniya, Sri Lanka \\ *Corresponding Author: avengad19@yahoo.com
}

Copyright (C) 2014 Horizon Research Publishing All rights reserved.

\begin{abstract}
Leaf Twister disease (LTD) is a major disease of onion (Allium ascalonicum L.) cultivated in Sri Lanka. The present study was aimed to determine molecular and pathogenic variations among the causal agents of onion leaf twister disease. The pathogens causing the LTD have been identified as Colletotrichum and Fusarium spp. Pathogenic variations of the fungal isolates, in terms of pathogenicity and virulence were determined in vivo by inoculation assays using red onion (variety Vethalan). LTD-infected plants were collected from farmer fields of four locations of Batticaloa district, Sri Lanka. Possible causal organism/s of LTD were isolated from three different parts of the infected plants, namely leaves, pseudostem and bulb. Morphologically-different six isolates of Colletotrichum and seven Fusarium isolates were obtained by isolations. Virulence of the Colletotrichum and Fusarium varied significantly among the isolates in terms of rapidity and extent of disease spread. Variety Vethalan was not completely resistant to any isolate of the two fungal genera tested. Genomic DNA of 13 isolates was extracted from each purified isolate using a modified CTAB method. PCR amplification was done with ITS1 and ITS4 primers to amplify the 5.8S-ITS subunit of the Colletotrichum isolates. The ITS2-rDNA subunit of Fusarium isolates was amplified by ITS-Fu1f and ITS-Fu1r primers. As expected 590 bp and 466 bp PCR products were resulted in by all Colletotrichum and Fusarium isolates, respectively. Colletotrichum isolates showed two polymorphic groups based on PCR-RFLP by RsaI, Hae III and Msp I. Fusarium isolates showed no polymorphism based on PCR-RFLP by Rsa I, Hae III and Msp I. Findings of the present study revealed that molecular and pathogenic variations exist among different isolates of Colletotrichum and pathogenic variations only exist among Fusarium isolates infecting red onion in Batticaloa district of Sri Lanka.
\end{abstract}

Keywords Allium Ascalonicum L., Genomic DNA, ITS Regions, PCR-RFLP, Polymorphism

\section{Introduction}

Onion (Allium ascalonicum L.) is one of the important cash crops grown in Sri Lanka and throughout the tropical world. It is the general practice by farmers in Sri Lanka, to cultivate onion as a monoculture repeatedly in the same farm fields. Therefore, it provides conducive conditions for the development of several economically-significant diseases. A disorder called "Leaf twister disease" (LTD) / disco disease has been reported since 1970 as a severe threat to bulb and seed crop production of onion. Colletotrichum gloeosporioides and Fusarium oxysporum have been identified as the predominant microorganisms associated with the LTD-infected onion tissues based on morphological analyses (Weeraratne, 1997; Kuruppu, 1999). Lower part of the leaves of LTD-infected plants develop sunken pale patches which later turn into grayish coloured lesions. Leaves show twisted appearance due to this infection. Since 1970 , the disease has been reported from many onion growing regions of Sri Lanka (e.g. Jaffna, Trincomalee, Putlam, Ratnapura, Matale, Anuradhapura etc.) having diverse agro-ecological conditions.

Due to environmental influences on the stability of morphological traits and the existence of intermediate forms, morphological criteria are not always adequate for reliable differentiation of Colletotrichum species. Similar limitations have been reported the identification of Fusarium species as well. The overlap of morphological characters and phenotypes among species makes the classification difficult. Molecular techniques provide alternative methods for taxonomic studies and are important tools in solving the problems of species delineation (MacLean et al., 1993). The ribosomal RNA genes (rDNA) possess characteristics that are suitable for the detection of pathogens at specific level. These rDNA are highly stable and exhibit a mosaic of conserved and diverse regions within the genome (Hibbet, 1992). Due to lower conservation of nucleotide sequences in the non transcribed and internal transcribed spacer (ITS) regions between the small and large nuclear rDNA subunits 
than in the coding regions, these have been used to detect recent evolutionary divergence within the species of fungal pathogens that have morphological complexities (Freeman et al., 2000; Arif et al., 2012).

Information available on genetically diverse pathogenic isolates would be useful to design effective management measures in terms of fungicide application and breeding for resistant germplasm of onion. The objective of our investigation was to determine the molecular and pathogenic diversity of the causal agents of onion leaf twister disease in Batticaloa district Sri Lanka.

\section{Materials and Methods}

\section{Isolation of Pathogenic Fungi}

LTD-infected red onion plant samples were collected from 4 farmer fields in Batticaloa district (Latitude: $7^{\circ} 43^{\prime} 0$ " $\mathrm{N}$; Longitude : $81^{\circ} 42^{\prime} 0^{\prime \prime} \mathrm{E}$; Altitude : $3 \mathrm{~m}$ ) Sri Lanka. Causal organisms of LTD were isolated separately from bulb, leaf and pseudo-stem parts of the plants showing typical LTD symptoms on plates of PDA medium and incubated at room temperature $\left(27 \pm 3{ }^{\circ} \mathrm{C}\right)$. Three replicates per location were used for isolation of fungal pathogens. Sub culturing was done on PDA plates supplemented with ampicillin (150 $\left.\mu \mathrm{gml}^{-1}\right)$ and streptomycin $\left(100 \mu \mathrm{gml}^{-1}\right)$ (Liu et al., 2010) to obtain pure cultures of Colletotrichum and Fusarium isolates. Single colony isolation method was used to obtain pure cultures of Colletotrichum and Fusarium isolates.

\section{Pathogenic Variation}

Red onion variety Vethalan was planted at a rate of one bulb/bag in polythene bags each having diameter and height of 13 and $16 \mathrm{~cm}$, respectively and filled with sterilized soil. Soil in one set of polythene bags was mixed with $10 \mathrm{ml}$ of spore suspension of each fungal isolate having a concentration of $1 \times 10^{5}$ conidia / $\mathrm{ml}$, prior to planting bulbs of red onion. A separate set of polythene bags planted with onion bulbs but not inoculated with fungal spore suspension was maintained as a control treatment. The above two types of treatments were replicated six times and arranged according to a completely randomized design. Plants were maintained in the glasshouse and Relative humidity and temperature were recorded throughout the experimental period. Number of leaves showing typical LTD symptoms out of total number of leaves of a plant and number of days taken to develop symptoms were recorded. Pathogenic variation among the isolates was determined based on disease severity in terms of percentage infected leaves of a plant and number of days taken to develop LTD symptoms (Number of days taken to start typical LTD symptoms of a plant).

Percentage infected leaves $=$

Number of leaves showing typical LTD symptoms at a particulartime x 100 Total number of leaves of a plant

\section{Extraction of DNA}

The genomic DNA was extracted from 7-8 days old fungal cultures and purified by the DNA extraction protocol described by Mc Gravey and Kaper (1991). The concentration of DNA was determined by spectrophotometer (Nano-spec, Shimadzu, Japan) and the samples were diluted to a final concentration of below $500 \mathrm{ng} / \mu \mathrm{l}$.

\section{PCR Amplification and PCR-RFLP}

The 5.8S-ITS region was amplified by using universal primers ITS1 (GCCGTAGGTGAACCTGCGG) and ITS4 (GCCTCCGCTTATTGATATGC) for Colletotrichum spp. (Pedro et al., 2000). The ITS2-rDNA region was amplified by PCR using primers Fulf (3'ACAACTCATAACCCTGTGAACAT 5') and the Fulr (3' CAGAAGTTGGG TGTTTTACGG 5') for Fusarium spp. (Arif et al., 2012). PCR reactions were performed in a total volume of $50 \mu 1$ containing $2 \mu 1$ of template DNA, $25 \mu 1$ Marster mix (Promega, USA), $5 \mu$ l of forward primer, $5 \mu l$ of reverse primer and $13 \mu \mathrm{l}$ of nuclease free water. The reaction mixtures were incubated in a thermocyclear (Takara, Japan) during 40 cycles, each consisting $1 \mathrm{~min}$ at $95^{\circ} \mathrm{C}, 1 \mathrm{~min}$ at $52^{\circ} \mathrm{C}$ and $1 \mathrm{~min}$ at $72^{\circ} \mathrm{C}$ for Colletotrichum ilates. and $1 \mathrm{~min}$ at $94^{\circ} \mathrm{C}, 1 \mathrm{~min}$ at $58^{\circ} \mathrm{C}$ and $2 \mathrm{~min}$ at $72^{\circ} \mathrm{C}$ for Fusarium isolates. PCR products were digested with the restriction enzymes Rsa I, Hae III and Msp I. PCR products and their restriction fragments were separated on 1 and $2 \%$ agarose gels with a 100 bp DNA size marker, respectively. After electrophoresis, gels were stained with ethidium bromide and the DNA bands were visualized under UV light.

\section{Data Analysis}

Data were analyzed by variance (ANOVA) using a SAS statistical package (version 9.1.3) and mean separation was done by Least Significance Difference (LSD). Correlation analyses were done between percentage infected leaves and number of days taken to develop symptoms.

\section{Results and Discussion}

\section{Isolation and Identification of Pathogenic Fungi}

Six Colletotrichum and 7 Fusarium isolates which were morphologically different were isolated from the LTD infected red onion samples collected from 4 different locations (Figures 1 and 2) in Batticaloa district of Sri Lanka. Identification of Colletotrichum and Fusarium isolates was based on morphological characters such as colony characters and size and shape of conidia according to descriptions of Simmonds (1965), Smith and Black, (1990) and Sutton (1992). Among the isolated fungal cultures, identification was focused on Colletotrichum and Fusarium species as $C$. gloeosporioides and $F$. oxysporum have been identified as the causal organisms of LTD (Weerarathne, 1997; Kuruppu, 1999). Ebenebe (1980) reported that onion LTD disease caused by Glomerella cingulata in northern Nigeria. Symptoms description of a disease of onion in Brazil appeared to resemble onion leaf twister disease and the disease was attributed to Colletotrichum gloeosporioides 
(Aquino and Da Wanderley, 1966). Dissanayake et al., (2009) obtained $18 F$. oxysporum isolates, $7 F$. verticillioides and 7 $F$. solani isolates from wilted welsh onion plants collected from nine farms located in six regions of Japan.

It is interesting to note that in our study $84 \%$ of the
Fusarium isolates were obtained from infected onion bulbs and $77 \%$ of the Colletotrichum isolates were obtained from infected leaves.

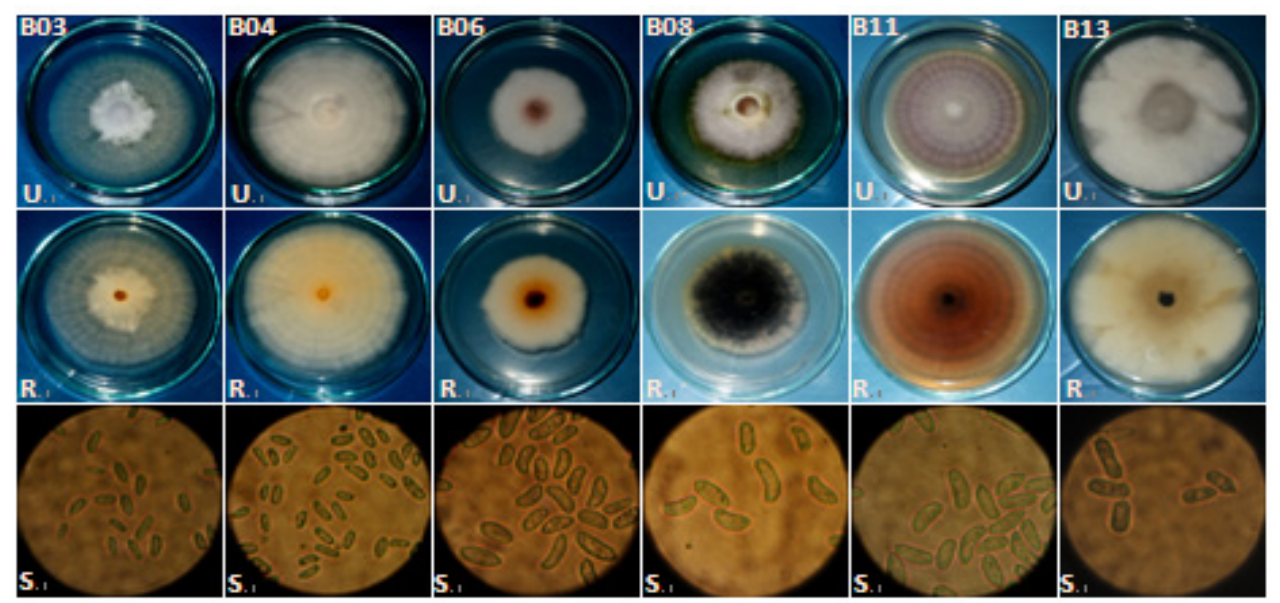

Figure 1. Colony appearance and shape of spore (U: Upper side; R: Reverse side; S: Spore shape) of Colletotrichum isolates on PDA at 7 days after incubation at $27+3^{\circ} \mathrm{C}$

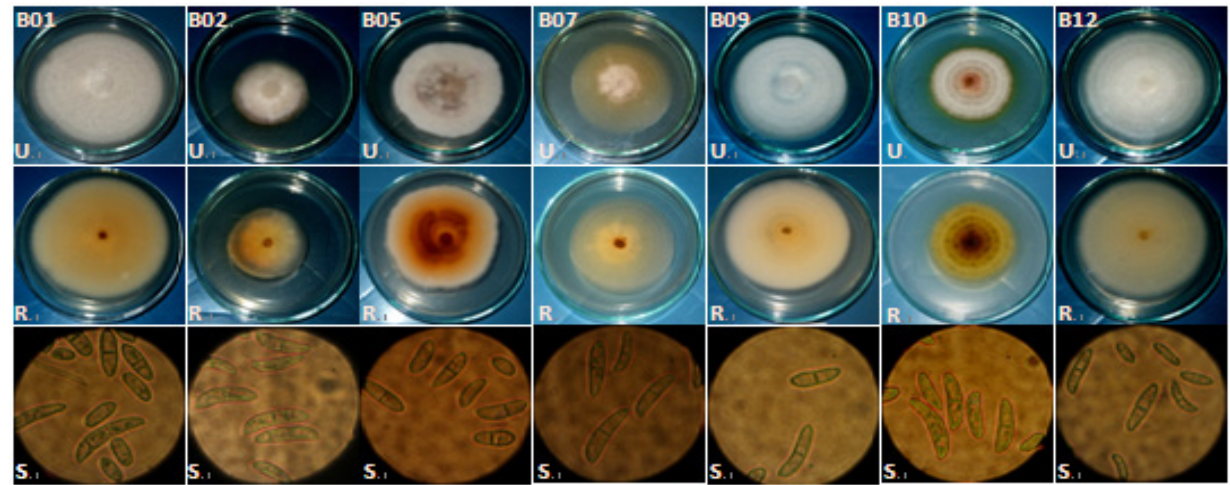

Figure 2. Colony appearance and shape of spore (U: Upper side; R: Reverse side; S: Spore shape) of Fusarium isolates on PDA at 7 days after incubation at $27 \pm 3^{\circ} \mathrm{C}$

\section{Pathogenic Variation}

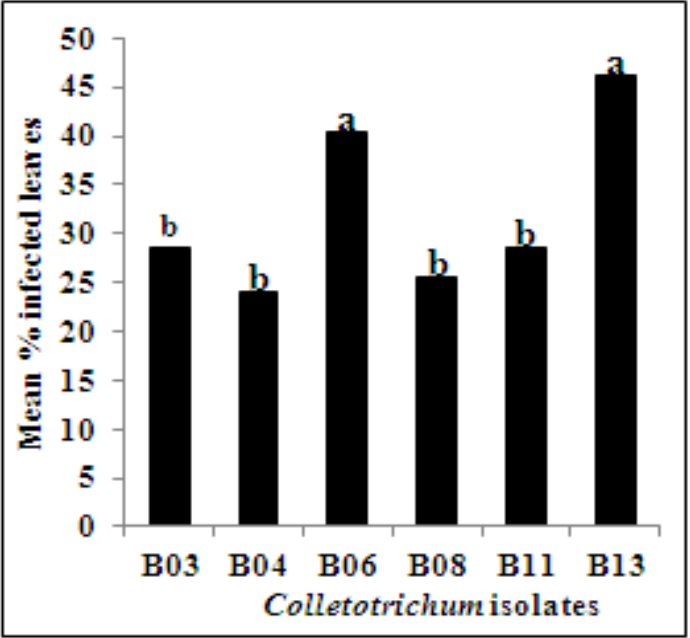

Figure 3. Virulence of different Colletotrichum isolates in terms of $\%$ leaves infected on red onion variety Vethalan

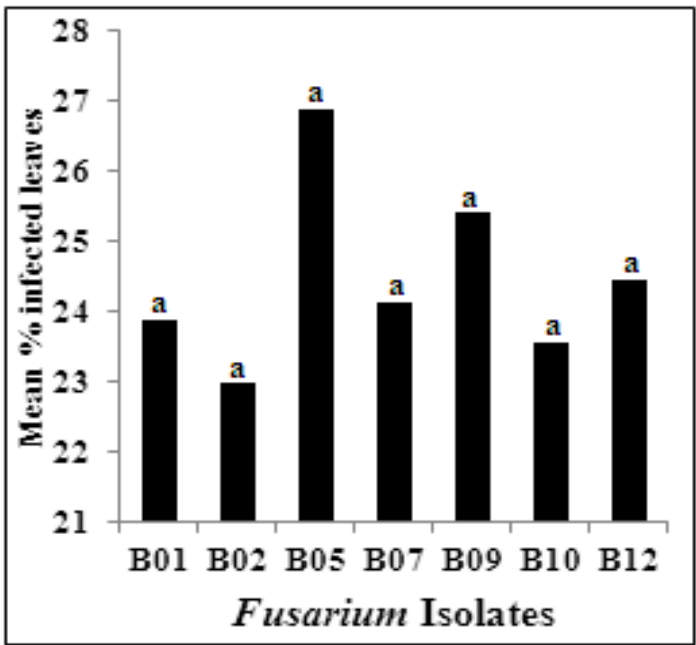

Figure 4. Virulence of different Fusarium isolates in terms of $\%$ leaves infected on red onion variety Vethalan 
Characteristic symptoms of LTD were developed at different intensities by all the isolates of Colletotrichum and Fusarium on onion plants at different days after inoculation of the pathogen. Control plants showed no symptoms development (i.e. set of pots containing onion bulbs without inoculum treatment was maintained as control treatment). Plants inoculated with Colletotrichum isolates showed initial twisting of leaves followed by chlorosis and abnormal elongation of the pseudostem. The plants resulted in very poor bulb formation. Plants inoculated with Fusarium isolates showed slight twisting, wilting and chlorosis of leaves and abnormal elongation of the pseudostem followed by bulb rotting. Percentage infected leaves varied among Colletotrichum isolates (Figure 3 ) significantly $(p<0.0001)$ whereas there was no significant difference among Fusarium isolates (Figure 4).
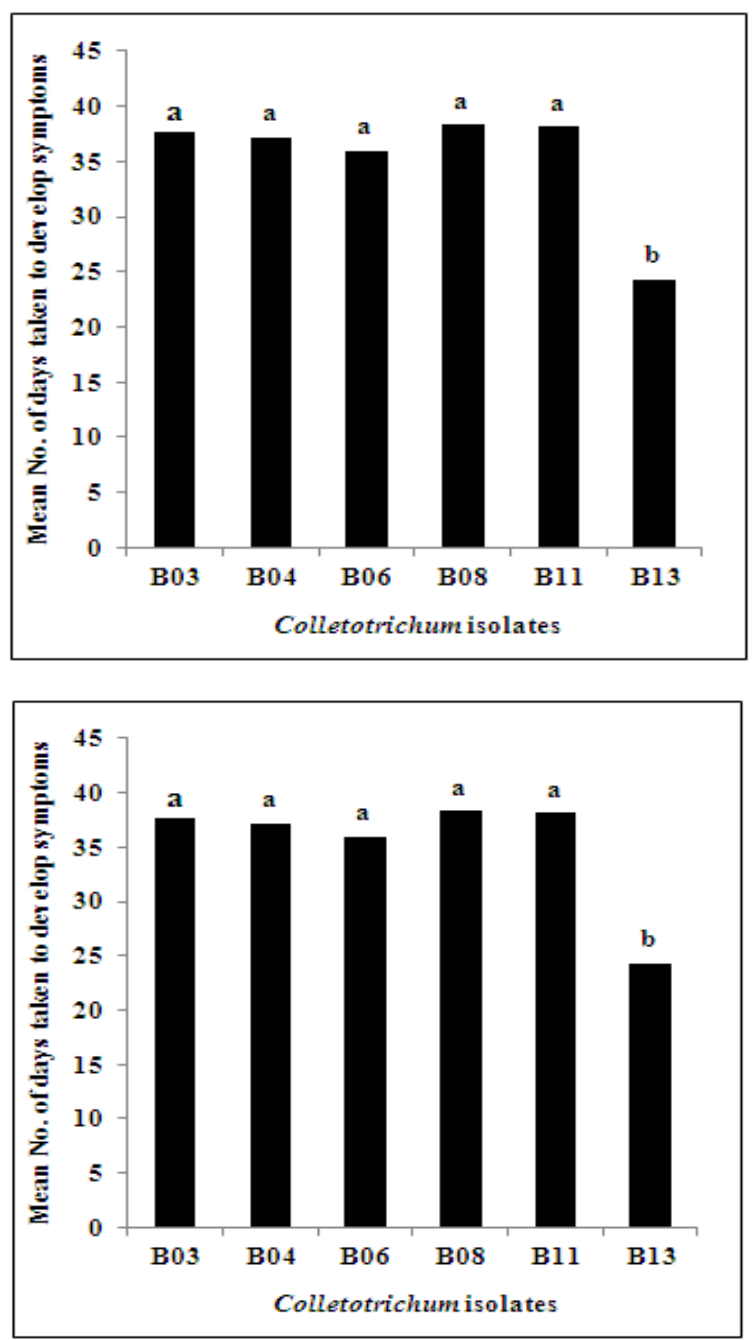

Figure 5. Virulence of different Colletotrichum isolates in terms of number of days taken to develop symptoms on red onion variety Vethalan

The highest percentage infected leaves among Colletotrichum isolates were reported by isolates $\mathrm{B} 6$ and B13. Isolates B03, B04, B08 and B11 were not significantly different in terms of percentage of infected leaves (Figure 3). The days taken to develop LTD symptoms vary among
Colletotrichum isolates (Figure 5) significantly $(\mathrm{p}<0.0001)$. The isolates taking higher number of days show a slower rate of disease development.

Accordingly, isolate B03, B04, B08 and B11 took a longer time to develop symptoms hence have a slower disease development. Lowest number of days was taken by the isolates B13, hence a rapid development of symptoms was observed. Therefore, it is clear that the different Colletotrichum isolates behave differently in terms of the number of leaves affected and the speed of disease development. In general, isolates B13 is high virulent on variety Vethalan in terms of the amount of disease caused and the rate of disease development.

However, a strong negative relationship (69.25\%) was identified between the percentage of infected leaves and the number of days taken to develop LTD symptoms for the Colletotrichum isolates tested. Above observations clearly showed that variety Vethalan did not show complete resistance to any of the Colletotrichum isolates tested (Figures 3 and 5). According to definition by Taylor et al. (2007) and Taylor and Ford (2007), the variations of quantitative measurements on disease development provide an idea of the diverse nature of the pathogen population in terms of their aggressiveness i.e. natural variation in virulence. The level of aggressiveness of isolates of a given pathogen is also an important consideration in resistance breeding programmes and disease control management. Host genotypes with partial resistance would result in lower level of infection which eventually will decrease the inoculum amount in the field to limit the potential of epidemics (Than et al., 2008).

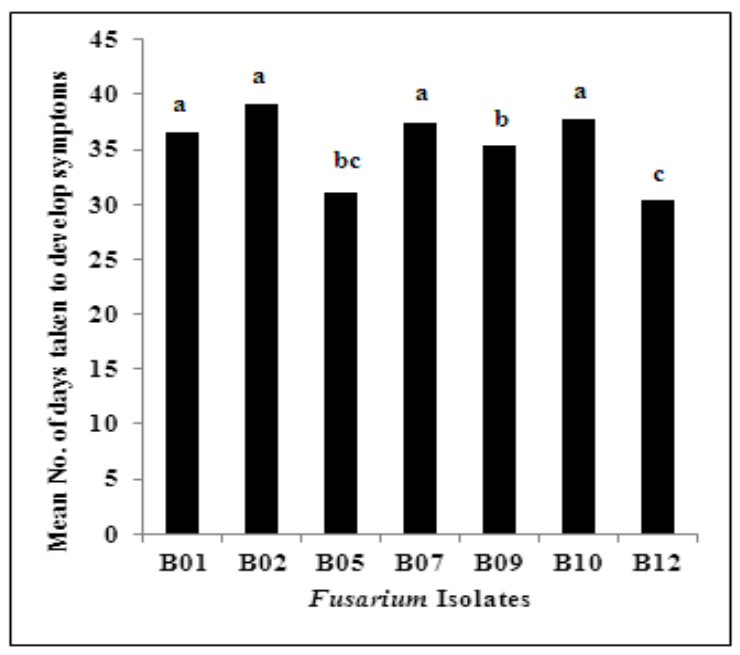

Figure 6. Virulence of different Fusarium isolates in terms of number of days taken to develop symptoms on red onion variety VethalanNumber of days taken to develop symptoms differ significantly $(p<0.0012)$ among the inoculated Fusarium isolates (Figure 6). Highest no. of days taken to develop symptoms was shown by Fusarium isolates B01, B02, B07 and B10 followed by B05 and B09. The lowest no. of days taken to develop symptoms was reported by isolate B12. Even though there is no significant difference among the Fusarium isolates on percentage of infected leaves (Figure 4). Accordingly, pathogenic behaviour of the Fusarium isolates can be considered highly diverse. 
Findings of the present study revealed the variation of aggressiveness of different Colletotrichum and Fusarium isolates when determined by two different disease assessment methods (e.g. percentage infected leaves and no. of days taken to develop symptoms). This is in agreement with the results reported by many researchers on comparative virulence of isolates of a range of fungal pathogens, to name a few, Colletotrichum coccodes causing black dot disease of potato (Daami-Remadi et al., 2010), C. gloeosporioides causing anthracnose of yam (Abang et al., 2001) and C. graminicola causing sorghum anthracnose (Rao et al., 1998).

Results of the present study identified the presence of several isolates of Colletotrichum and Fusarium within one of the onion-growing regions of Sri Lanka, the differential response of those isolates to currently-used fungicide and the variation of virulence of different isolates of the two fungal pathogens. Such biological and pathological information would be highly useful to modify chemical-based management measures and develop crop improvement programmes for LTD pathosystem.

\section{Molecular Variation}

The aim of this investigation was to determine the genomic variation of Colletotrichum and Fusarium isolates causing LTD disease of onion. Identification of Fusarium species is ideally carried from growth on carnation leaf agar, an effective medium for macroconidium production, however, this medium is not readily available to the non-specialist. Recently many investigations have been focused on molecular approaches for identification and speciation of moulds including Fusarium species (Mirhendi et al., 2010). In the present study, all the Colletotrichum and Fusarium isolates resulted in the expected sized PCR products of 590 (Figure 7) and 466 bp (Figure 9) respectively, when amplified by ITS1 \& ITS4 and ITS-Fu1f \& ITS-Fu1r primers respectively. Figueiredo et al. (2012) reported that the amplification of the ITS1-5.8S-ITS2 of the rDNA region using the universal primers ITS1 and ITS4 produced a fragment of approximately 590 bp for $C$. gloeosporioides isolates and his report also confirming previously reported results (Abang et al., 2002; VilaNova et al., 2011).

The PCR-RFLP profiles of all Colletotrichum and Fusarium isolates given by the three restriction endonucleases (i.e. Rsa I, Hae III and Msp I) are shown respectively in Figures 8 and 10. Based on PCR-RFLP analysis, 2 polymorphic groups were observed among the isolates of Colletotrichum spp. when digested with Rsa I, Hae III and Msp I. However, no polymorphism was observed among the isolates of Fusarium when digested with Rsa I, Hae III and Msp I (Figure 10). Colletotrichum isolates B03, B04, B06, B08 and B11 belonged to one group and B13 belonged to another polymorphic group. Restriction pattern generated from the DNA region spanning the ITS and 5.8S rRNA gene, allowed to differentiate among Colletotrichum isolates. The ITS regions, which are much more variable than the rRNA encoding gene (Burns et al., 1991). Although the sequence data provide more information than the restriction pattern analysis, this method can be useful in species differentiation.

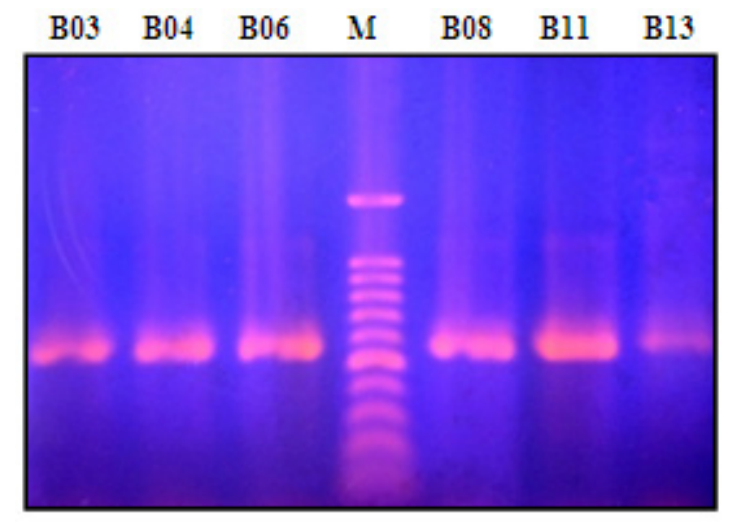

Figure 7. PCR products of 6 Colletotrichum isolates when amplified with ITS1 / ITS2 primers. M - Molecular weight markers (100bp ladder, Promega, USA)

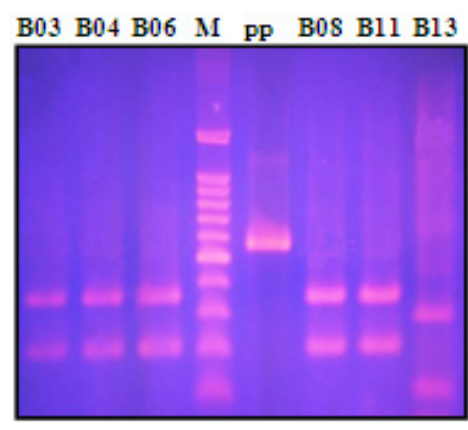

(a)

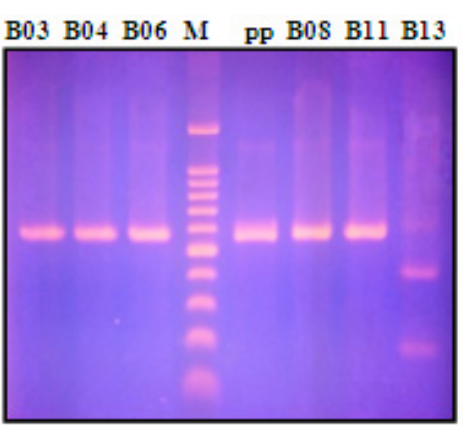

(b)

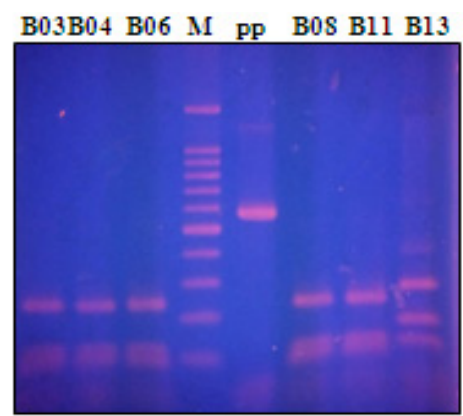

(c)

Figure 8. ITS region restriction pattern exhibited by 6 Colletotrichum isolates after digestion with restriction endonuclease Msp I (a), Rsa I (b) and Hae III (c). pp - Undigested PCR product, and M - Molecular weight markers (100bp ladder, Promega, USA). 


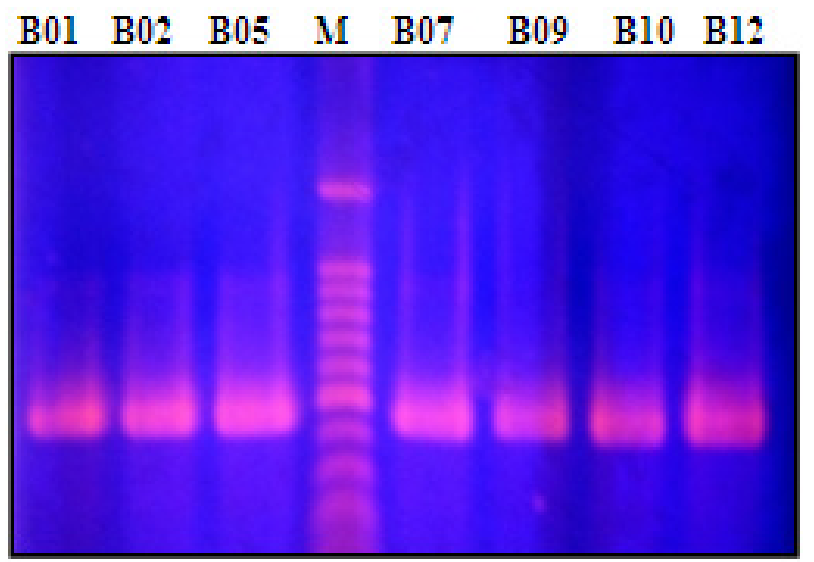

Figure 9. PCR products of 12 Fusarium isolates amplified by ITS-Fu1f/ ITS-Fu1r primers. M-Molecular weight markers (100bp ladder, Promega, USA)

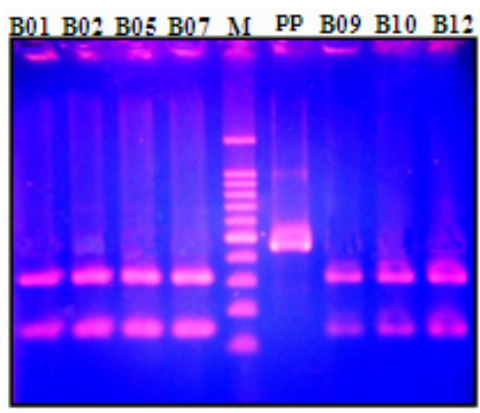

(a)

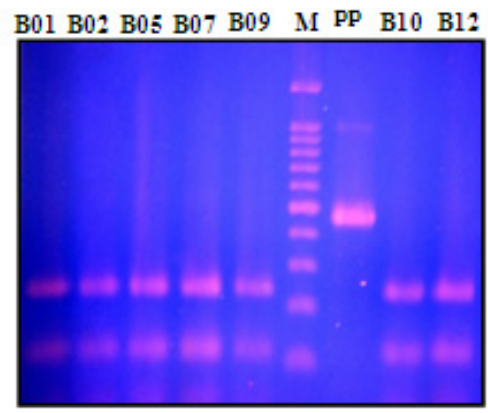

(b)

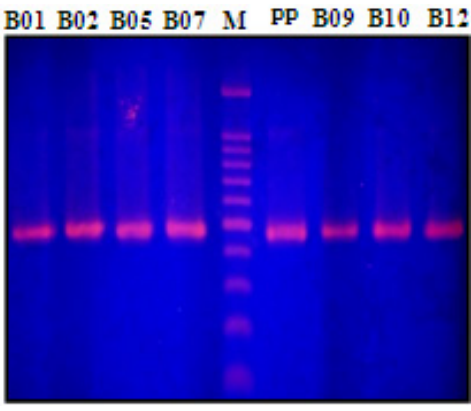

(c)

Figure 10. PCR-RFLP pattern exhibited by 7 Fusarium isolates after digestion with restriction endonuclease Msp I (a), Hae III (b) and Rsa I (c). pp Undigested PCR-product and M- Molecular weight markers (100bp ladder, Promega, USA)

In the present study used primer sets were successful in amplifying the expected sized PCR products, hence useful in detecting the two species in infected plant parts and also for confirmation of the two species identified by morphological methods. Moreover, a reasonable level of genomic variation could be identified when the PCR-RFLP was done with $R s a \mathrm{I}$, Hae III and Msp I. However, genomic variation through PCR-RFLP was not successful when the amplified products were digested with Rsa I, Hae III and Msp I for the tested Fusarium spp. Hence, further sequencing analyses on PCR products have to be done and that will be helpful to further effective measures of onion LTD control and breeding programs.

\section{Conclusions}

The present study revealed molecular and pathogenic variations exist among different isolates of Colletotrichum and pathogenic variations only exist among Fusarium isolates infecting red onion in Batticaloa district of Sri Lanka.

\section{Acknowledgements}

Financial assistance by University Grants Commission, Sri Lanka is acknowledged.

\section{REFERENCES}

[1] Abang, M. M., Green, K. R., Wanyera, N. W. and Iloba, C. (2001). Characterization of Colletotrichum gloeosporioides Penz. from yam (Dioscorea spp.) in Nigeria. In: Akoroda AO, Ngeve JM. (Eds), Root Crops in the 21st Century. Proceedings of the 7th Triennial Symposium of the International Society for Tropical Root Crops-Africa Branch, Cotonou, Be'nin, 613-615.

[2] Abang, M. M., Winter, S., Green, K. R., Hoffmann, P. (2002). Molecular identification of Colletotrichum gloeosporioides causing yam anthracnose in Nigeria. Plant Pathology, 51, 63-71.

[3] Aquino, M. I. N. and Da Wanderley, L. J. (1966). O “ mal das sete voltas' nos cebolais de sao franoisc Institute of Agronomic de pernambuco Boletim technico, 16, 42.

[4] Arif, M., Chawla, S., Zaidi, N. W., Rayar, J. K., Variar, M. and Singh, U. S. (2012). Development of specific primers for genus Fusarium and $F$. solani using rDNA sub-unit and transcription elongation factor (TEF-1 $\alpha$ ) gene. African Journal of Biotechnology, 11(2), 444-447.

[5] Bruns, T. D., White, T. J. and Taylor, J. W. (1991). Fungal molecular systematic. Annual Review of Ecology and Systematics, 22, 525-564.

[6] Daami-Remadi, M., Bouallegue, R., Jabnoun-Khiareddine, H. 
and Mahjoub, E. M. (2010). Comparative aggressiveness of Tunisian Colletotrichum cocodes isolates on potato Assessed via Black Dot severity, plant growth and yield loss. Pest Technology, 4(1), 45-53.

[7] Dissanayake, M. L. M., Kashima, R., Tanaka, S. and Ito, S. I. (2009). Pathogenic variation and molecular characterization of Fusarium species isolated from wilted Welsh onion in Japan. Journal of General Plant Pathology, 75, 37-45.

[8] Ebenebe, A. C. (1980). Onion twister disease caused by Glomerella cingulata in northern Nigeria. Plant Disease, 64(11), 1030-1032.

[9] Figueirêdo, L. C., Figueirêdo, G. S., Quecine, M. C., Cavalcanti,F. C. N., Santos, A. C., Costa, A. F., Oliveira, N. T. and Azevedo, J. L. (2012). Genetic and pathogenic diversity of Colletotrichum gloeosporioides, the causal agent of cashew anthracnose. Indian Journal of Fundamental and Applied Life Sciences, 2(1), 250-259.

[10] Freeman, S., Minz, D., Jurkevitch, E., Maimon, M. and Shabi, E. (2000). Molecular analyses of Colletotrichum species from almond and other fruits. Phytopathology, 90, 608-614.

[11] Hibbet, D. S. (1992). Ribosomal RNA and fungal systematics. Transactions of the Mycological Society of Japan, 33, 533-556.

[12] Kuruppu, K. U. (1999). First report of Fusarium oxysporum causing a leaf twisting disease on Allium cepa var. ascalonicum in Sri Lanka. Plant Disease, 83(7), 695-698.

[13] Liu, C., Liu, T., Yuan, F. and Gu, Y. (2010). Isolating endophytic fungi from evergreen plants and determining their antifungal activities. African Journal of Microbiology Research, 4(21), 2243-2248.

[14] MacLean, D.J., Braithwaite, K.S., Manners, J.M. \& Irwing, J.A.G. (1993). How do we identify and classify fungal pathogens in the era of DNA analysis?. Advances in Plant Pathology, 10, 207-244.

[15] Mc Garvey, P. and Kaper, J.M. (1991). A simple and rapid method for screening transgenic plants using the PCR. Biotechniques, 11, 428-432.

[16] Mirhendi, H., Ghiasian, A., Vismer, H. F., Asgary, M. R., Jalalizand, N., Arendrup, M. C. and Makimura, K. (2010). Preliminary identification and typing of pathogenic and toxic Fusarium species using restriction digestion of ITS1-5.8 rDNA region. Iranian Journal of Public Health, 39(4), 35-44.

[17] Pedro, V., Martiniez, C., Barrio, E., Dolores, G. and Querol,
A. (2000). Identification of Colletotrichum species for anthracnose of strawberry based on the international transcribed spacers of the ribosomal region. FEMS Microbiology Letters, 189, 97-101.

[18] Rao, V. P., Thakur, R. P. and Mathur, K. (1998). Morphological and pathogenic diversity among grain sorghum isolates of $\mathrm{C}$. gramanicola in India. Indian Phytopathology, 51(2), 164-174.

[19] Simmonds, J. H. (1965). A study of the species of Colletotrichum causing ripe fruit rots in Queensland. Journal of Agricultural Animal Sciences, 22, 437-459.

[20] Smith, B. J. and Black, L. L. (1990). Morphological, cultural and pathogenic variation among Colletotrichum species isolated from strawberry. Plant Disease, 74, 69-76.

[21] Sutton, B. C. (1992). The genus Glomerella and its anamorph Colletotrichum. In: Colletotrichum : biology, pathology and control (Eds. J.A. Bailey and M.J. Jeger). CAB International, Wallingford: 1-26.

[22] Taylor, P. W. J. and Ford, R. (2007). Diagnostics, Genetics diversity and pathogenic variation of ascochyta blight of cool season food and feed legumes. European Journal of Plant Pathology, 127-133.

[23] Taylor, P. W. J., Mongkolporn, O., Than, P. P., Montri, P., Ranathunge, N., Kanchana-udonkarn, C., Ford, R., Pongsupasamit, S. and Hyde, K. D. (2007). Pathotypes of Colletotrichum spp. Infecting Chilli Peppers and Mecha-nisms of Resistance. In: Oh, D.G., Kim, K.T. (Eds.), Abstracts of the First International Symposium on Chilli Anthracnose. National Horticultural Research Institute, Rural Development of Administration, Republic of Korea, p.29.

[24] Than, P. P., Jeewon, R., Hyde, K. D., Pongsupasamit, S., Mongkolporn, O. and Taylor, P. W. J. (2008). Characterization and pathogenicity of Colletotrichum species associated with anthracnose disease on chilli (Capsicum spp.) in Thailand. Plant Pathology, 57(3), 562-572.

[25] Vila Nova, M.X., Borges, L. R., De Sousa, A. C. B., Brasileiro, B. T. R. V., Lima, E. A. L. A., Da Costa, A. F. and De Oliveria, N. T. (2011). Pathogenicity for onion and genetic diversity of isolates of the pathogenic fungus Colletotrichum gloeosporioides (Phyllachoraceae) from the state of Pernambuco, Brazil. Genetics and molecular Research, 10(1), 311-320.

[26] Weeraratne, G. W. A. P. (1997). Leaf twister disease of onion (Allium cepa L.). Tropical Agriculturist, 151, 25-33. 